\title{
PENGARUH MOTIVASI TERHADAP KINERJA KARYAWAN PADA PT. FAST FOOD INDONESIA (KFC) PONDOK INDAH PLAZA, JAKARTA SELATAN
}

\author{
Suwanto \\ Fakultas Ekonomi, Universitas Pamulang \\ Email: dosen01813@unpam.ac.id
}

\begin{abstract}
Purpose. This study aims to determine the effect of motivation on employee performance at PT. Indonesian Fast food (KFC) Pondok Indah Plaza, South Jakarta.

Methods. The research method used in this study is an associative method and data collection using a questionnaire technique. The sample in this study were all employees of PT. Fast food Indonesia (KFC) Pondok Indah Plaza South Jakarta, amounting to 40 people. The analysis method used in data processing is validity test, reliability test, product moment correlation, determination coefficient and simple linear regression test.
\end{abstract}

Findings. Based on the calculation results, the correlation value ( $r$ ) between the motivation variable $(X)$ and the employee performance variable $(Y)$ is 0.634 or $63.4 \%$, meaning that motivation has a positive effect on employee performance at PT. Indonesian Fast food (KFC) Pondok Indah Plaza, South Jakarta. Meanwhile, the coefficient of determination is 0.366 or $36.60 \%$. This means that motivation has $36.60 \%$ effect on employee performance, and after the significance test was carried out using the "t test", it was found that $t$ count $>t$ table or 4.691> 2.024, while 63.40\% was influenced by other factors not examined by the researcher.

Implication. To increase motivation and performance of the company or leadership, it is necessary to increase social needs for employees such as relationships with other employees, the need for self-actualization, the need to feel involved with the company because employees need to be involved in anything related to their duties so that employees feel given opportunities to socialize and actualize their existence, because if employees feel that they are trusted and recognized by the company, the employees will improve their performance in carrying out their work.

Keywords. Motivation and Employee performance.

\begin{abstract}
ABSTRAK
Tujuan. Penelitian ini bertujuan untuk mengetahui pengaruh motivasi terhadap kinerja karyawan PT. Fastfood Indonesia (KFC) Pondok Indah Plaza Jakarta Selatan.

Metode. Metode penelitian yang dipergunakan dalam penelitian ini adalah metode asosiatif dan pengumpulan data dengan teknik kuesioner. Sampel dalam penelitian ini adalah seluruh karyawan PT. Fastfood Indonesia (KFC) Pondok Indah Plaza Jakarta Selatan yang berjumlah 40 orang. Metode analisis yang digunakan dalam pengolahan data adalah uji validitas, uji realibilitas, korelasi product moment, koefisien determinasi dan uji regresi linear sederhana.
\end{abstract}

Hasil. Berdasarkan hasil perhitungan, nilai korelasi (r) antara variabel motivasi (X) dengan variabel kinerja karyawan (Y) adalah 0,634 atau 63,4 \%, artinya motivasi berpengaruh positif terhadap kinerja karyawan pada PT. Fastfood Indonesia (KFC) 
Pondok Indah Plaza Jakarta Selatan. Sedangkan hasil koefisien determinasinya sebesar 0,366 atau 36,60 \%. Hal ini berarti bahwa motivasi berpengaruh 36,60 \% terhadap kinerja karyawan, dan setelah dilakukan uji signifikasi dengan menggunakan "uji t", diperoleh bahwa $t_{\text {hitung }}>t_{\text {tabel }}$ atau 4,691 $>2,024$, sedangkan 63,40\% dipengaruhi oleh faktor lain yang tidak diteliti oleh peneliti.

Implikasi. Untuk meningkatkan motivasi dan kinerja perusahaan atau pimpinan perlu meningkatkan kebutuhan sosial untuk karyawan seperti hubungan dengan karyawan lain, kebutuhan akan aktualisasi diri, kebutuhan perasaan ikut serta dengan perusahaan karena karyawan perlu diikut sertakan dalam apapun yang menyangkut tugasnya agar karyawan merasa diberikan kesempatan bersosialisasi dan mengaktualisasikan keberadaannya, karena apabila karyawan merasa diberikan kepercayaan dan diakui keberadaannya oleh perusahaan karyawan akan meningkatkan kinerjanya dalam melaksanakan pekerjaannya.

Kata Kunci. Motivasi Dan Kinerja Karyawan.

\section{Pendahuluan}

Pada dasarnya tenaga kerja memiliki potensi yang besar untuk menjalankan aktifitas perusahaan. Potensi setiap sumber daya manusia yang ada dalam perusahaan harus dapat dimanfaatkan dengan sebaik baiknya, sehaingga mampu memberikan hasil yang maksimal. Dalam menjalankan suatu perusahaan maka aspek yang cukup penting adalah aspek sumber daya manusia, manusia selalu berperan aktif dalam setiap kegiatan organisasi, karena manusia menjadi perencana, pelaku dan penentu dalam terwujudnya tujuan organisasi. Tujuan tidak akan terwujud tanpa peran aktif karyawan. Perusahaan dan karyawan merupakan dua hal yang saling membutuhkan. Jika karyawan berhasil membawa kemajuan bagi perusahaan, keuntungan yang diperoleh akan dipetik oleh kedua belah pihak. Sementara itu di dunia pada saat ini sedang menghadapi beberapa tantangan utama, pertama perubahan lingkungan/ iklim bisnis yang cepat diiringi dengan menigkatkan kualitas dan kebutuhan konsumen. Dari suatu sisi perubahan yang cepat tersebut mengakibatkan terjadinya dinamika pekerjaan berupa perubahan dan perkembangan yang menuntut keterampilan dan keahlian yang melebihi dari sebelumnya. Konsumen selalu menginginkan keinginan dan kebutuhannya dapat terpenuhi secara berkualitas dan memuaskan.

Menurut Edwin B Flippo dalam buku Hasiubuan (2013:145), motivasi adalah: "Suatu keahlian, dalam mengarahkan pegawai dan organisasi agar mau bekerja secara berhasil, sehingga keinginan para pegawai dan tujuan organisasi sekaligus tercapai". Setiap karyawan mempunyai perbedaan tujuan individual sebagai akibat dari latar belakang pendidikan, pengalaman, dan lingkungan masyarakat yang berbeda. Maka hal ini akan terbawa kedalam pekerjaaannya sehingga akan mempengaruhi sikap dan tingkah laku karyawan tersebut dalam melaksanakan tugas dan pekerjaannya. Disamping itu suasana batin atau psikoligis seseorang karyawan secara individu dalam organisasi yang juga mempunyai pengaruh besar dalam lingkungan kerjanya terhadap pelaksanaan pekerjaannya itu. Hal ini berarti karyawan memerlukan motivasi kerja yang sangat kuat agar bersedia melaksanakan pekerjaan secara bersemangat secara positif, berkinerja tinggi dan menghasilkan produktifitas kerja yang memuaskan.

Menurut Ansory dan Meithiana (2018:208) kinerja karyawan adalah hasil kerja secara kualitas dan kuantitas yang dicapai seseorang pegawai dalam melaksanakan tugasnya sesuai dengan tanggung jawab yang diberikan kepadanya. Pelaksanaan pekerjaan akan lebih efektif apabila didukung dengan keyakinan dan motivasi yang tinggi.dengan adanya keyakinana akan mendorong seseorang untuk bertanggung jawab terhadap pekerjaanya, sehingga dapat mengarahkan perilaku kerjanya demi tercapainya tujuan yang diinginkan. Kinerja sangat erat hubungannya dengan produktivitas kerja karyawan. Produktivitas karyawan secara individu akan mendukung keberhasilan organisasi. kinerja dalam perusahaan merupakan jawaban dari berhasil atau tidaknya tujuan perusahaan yang telah ditetapkan. Para atasan atau manajer sering tidak memperhatikan hil ini kecuali sudah sangat buruk atau segala sesuatunya menjadi 
serba salah. Terlalu sering manajer tidak mengetahui berapa buruknya kinerja yang merosot sehingga perusahaan mengalami krisis yang serius, kesan kesan bururk perusahaan yang mendalam berakibat turunnya kinerja. Kinerja merupakan suatu istilah secara umum yang digunakan untuk sebagian atau seluruh tindakan atau aktivitas dari suatu organisasi padasuatu periode dengan referensi pada sejumlah standar seperti biaya-biaya masa lalu atau yang diproyeksikan, dengan dasar efesiensi, pertanggung jawaban atau akuntabilitas manajemen dan semacamnya.

Dengan memberikan sarana untuk mencegah ketidakpuasan dengan cara membuat pekerjaaan menjadi menyenangkan, karyawan lebih puas dengan pekerjaan yang mereka senang kerjakan daripada yang membosankan. Sehingga kepentingan pribadi dan professional dapat di sesuaikan. Pada penelitian ini penulis memilih PT. Fast Food Indonesia atau Kentucky Fried Chicken (KFC) Pondok Indah Plaza sebagai objek penelitian. Restoran KFC mempunyai konsep sebagai restoran cepat saji dimana produkproduk yang ditawarkan sangat bervariatif. KFC merupakan pemimpin pasar dalam restoran cepat saji yang berasal dari Amerika Serikat yang menu utamanya adalah ayam goreng. Masalah yang timbul adalah apakah motivasi yang menyangkut dalam hal ini yaitu dukungan dari atasan kerja sehingga kekuatan dan kecendrungan dari ekspektasi atau pengarapan karyawan untuk bekerja secara benar selain kebutuhan atas imbalan atau insentif menyebabkan kinerja karyawan yang lebih baik atau sebaliknya.

Pemilihan KFC sebagai objek penelitian merupakan tempat yang paling strategis dan dianggap memiliki indikator dalam bidang motivasi dan kinerja karyawan. Selain itu lokasi penelitian dekat dengan peneliti sehingga sangat mendukung dalam pelaksanaan penelitian. Data penelitian sebagai berikut.

Tabel 1.1 Data Quartaly QSC (Quality, Service And Cleanliness) Tahun 2019 PT. Fast Food Indonesia (KFC) Cabang Pondok Indah Plaza

\begin{tabular}{|l|lllll|l|}
\hline Periode & Counter & Kitchen & Management & Total & Grade \\
\hline Oktober & 88.52 & 85.85 & 81.63 & 85.33 & B \\
November & 87.89 & 82.09 & 77.19 & 82.39 & B \\
Desember & 77.52 & 78.8 & 77.19 & 77.83 & C \\
\hline In & & & & & \\
Quartaly & $\mathbf{8 4 . 6 4}$ & $\mathbf{8 2 . 2 4}$ & $\mathbf{7 8 . 6 7}$ & $\mathbf{8 1 . 8 5}$ & B \\
\hline
\end{tabular}

Sumber : Data dari Manajer Restoran (2020)

Sehubungan dengan hal itu maka penulis mengadakan pemnelitian lebih jauh terhadap hubungan antara motivasi dengan kinerja karyawan pada PT. Fast Food Indonesia (KFC) Pondok Indah Plaza yang bergerak pada bidang restoran cepat saji. Berkaitan dengan uraian diatas, maka penulis tertarik untuk mengangkat topik dengan judul "Pengaruh Motivasi Terhadap kinerja karyawan pada PT. Fast Food Indonesia (KFC) Pondok Indah Plaza Jakarta Selatan"'.

\section{Kajian Pustaka dan Hipotesis}

Motivasi. Menurut Ansory dan Meithiana (2018:259) Motivasi kerja berasal dari kata latin Movere yang berarti dorongan atau menggerakan dan bahasa inggrisnya To Move. Motivasi adalah sebuah dorongan atau alasan yang mendasari semangat dalam melakukan sesuatu. Motivasi adalah hal-hal yang menimbulkan dorongan, dan motivasi kerja yang merupakan pendorong semangat sehingga menimbulkan suatu dorongan. Pemberian motivasi ini diharapkan setiap individu atau karyawan bisa bekerja keras dan antusias untuk mencapai prestasi kerja yang tinggi secara etimologi motivasi berasal dari kata "motif", motif adalah daya upaya yang mendorong seseorang untuk melakukan sesuatu. Motivasi kerja merupakan cara mengarahkan daya dan potensi bawahan, agar mau bekerja sama secara produktif berhasil mencapai suatu dan mewujudkan tujuan yang telah ditentukan. 
Kinerja Karyawan. Menurut Hasibuan (2014:194) “Kinerja adalah hasil yang diperoleh untuk organisasi yang dihasilkan karyawan dalam melaksanakan tugas dan tanggung jawabnya selama satu periode waktu". Menurut Mangkunegara (2013:67) mengemukakan, bahwa: "Pengertian kinerja adalah hasil kerja secara kuantitas dan kualitas yang dicapai oleh seseorang pegawai adalah dalam melaksanakan tugasnya sesuai dengan tanggung jawab yang diberikan kepadanya". Kinerja merupakan suatu kinerja atau hasil kerja baik kualitas maupun kuantitas yang telah dicapai oleh seseorang karyawan dalam melaksanakan fungsi, tugas, dan tanggung jawabnya dalam pekerjaan.

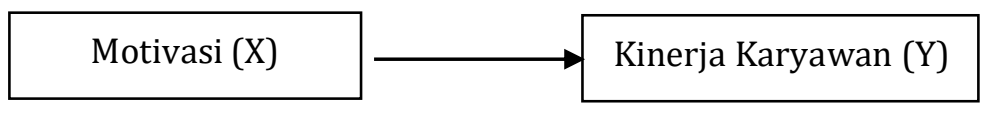

Gambar 1. Model Penelitian

\section{Metode Penelitian}

Jenis penelitian yang digunakan adalah penelitian asosiatif, penelitian asosiatif yaitu penelitian yang bertujuan untuk mengetahui hubungan antara dua variabel atau lebih. Dengan tujuan untuk mengetahui pengaruh antara variabel bebas dalam hal ini adalah variabel variabel bebasnya adalah Motivasi (X) variabel terikat dalam hal ini adalah variabel kinerja (Y).Yang menjadi populasi dalam penelitian ini adalah seluruh karyawan pada PT. Fast Food Indonesia (KFC) Cabang Pondok Indah Plaza, Jakarta Selatan yang berjumlah 40 orang. Dalam penelitian ini, penulis menggunakan sampling jenuh. Sampling Jenuh adalah teknik penentuan sampel bila semua anggota populasi digunakan sebagai sampel. Hal ini sering digunakan untuk penelitian dengan jumlah sampel dibawah 100 orang, atau untuk penelitian yang ingin membuat generalisasi dengan tingkat kesalahan yang sedikit atau kecil. Jadi sampel dalam penelitian ini adalah 40 responden.

\section{Hasil Penelitian dan Pembahasan}

\section{Analisis Variabel Motivasi (X)}

Motivasi merupakan serangkaian proses yang membangkitkan (arouse), mengarahkan (direct), dan menjaga (maintain) perilaku masusia menuju pada pencapaian tujuan. Motivasi juga berkepentingan dengan pilihan yang dilakukan orang dan arah perilaku mereka. Sedangkan perilaku menjaga atau memelihara berapa lama orang akan terus berusaha untuk mencapai tujuan.

Motivasi yang terdapat pada PT. Fast Food Indonesia (KFC), mendapat respon sangat baik, penulis menyimpulkan berdasarkan hasil jawaban seluruh responden yang berjumlah 40 karyawan dengan 10 pernyataan, yang menjawab "Sangat setuju" bernilai 163 atau 40,75\%, jawaban "Setuju" bernilai 143 atau 35,75\%, jawaban "Ragu" bernilai 74 atau 18,5\%, jawaban "Tidak setuju" bernilai 14 atau 3,5\%, dan jawaban "Sangat tidak setuju" senilai 6 atau 1,5\%.

\section{Analisis Variabel Kinerja (Y)}

Kinerja merupakan gaya manajemen dalam mengelola sumber daya manusia yang berorientasi pada kinerja yang melakukan proses komunikasi secara terbuka dan berkelanjutan dengan menciptakan visi bersama dan pendekatan strategis serta terpadu sebagai kekuatan pendorong untuk mencapai tujuan organisasi.

Kinerja yang terdapat pada PT. Fast Food Indonesia (KFC), mendapat respon sangat baik, penulis menyimpulkan berdasarkan hasil jawaban seluruh responden yang berjumlah 40 karyawan dengan 10 pernyataan, yang menjawab "Sangat setuju" bernilai 64 atau $16 \%$, jawaban "Setuju" bernilai 140 atau 35\%, jawaban "Ragu" bernilai 90 atau 22,5\%, jawaban "Tidak Setuju" bernilai 103 atau 22,75\%, dan jawaban "Sangat tidak setuju" senilai 3 atau $0,75 \%$. 


\section{Pembahasan Verifikatif}

Pembahassan verifikatif dimaksudkan untuk membahas perihal pengaruh dan signifikansinya serta, pembahasan keterkaitan teori yang mendukung yang diselaraskan dengan hasil pengolahan data. Berdasarkan perhitungan regresi linear sederhana yang telah dilakukan bahwa koefisien korelasi antara motivasi terhadap kinerja karyawan sebesar 0,605 dan koefisien determinasi 36,60 \%. Hal ini berarti terdapat pengaruh yang kuat antara motivasi dan kinerja karyawan, dan berdasarkan pengujian hipotesis yang telah dilakukan dengan "Uji t $\mathbf{t}$ " diperoleh bahwa $\mathbf{t}$ hitung $=4,691$ dan setelah dibandingkan dengan $\mathbf{t}$ tabel pada taraf signifikan $5 \%$ dan $\mathrm{n}=40$ menunjukkan $\mathrm{t}$ tabel $=2,024$. Karena $\mathrm{t}$ hitung lebih besar dari $\mathbf{t}$ tabel $(4,691>2,024)$ dengan demikian terbukti bahwa "Terdapat pengaruh yang signifikan antara motivasi terhadap kinerja karyawan pada PT. Fast Food Indonesia (KFC) Cabang Pond ok Indah Plaza".

\section{Kesimpulan}

Motivasi merupakan serangkaian proses yang membangkitkan (arouse), mengarahkan (direct), dan menjaga (maintain) perilaku masusia menuju pada pencapaian tujuan. Motivasi juga berkepentingan dengan pilihan yang dilakukan orang dan arah perilaku mereka. Sedangkan perilaku menjaga atau memelihara berapa lama orang akan terus berusaha untuk mencapai tujuan. Kinerja merupakan gaya manajemen dalam mengelola sumber daya manusia yang berorientasi pada kinerja yang melakukan proses komunikasi secara terbuka dan berkelanjutan dengan menciptakan visi bersama dan pendekatan strategis serta terpadu sebagai kekuatan pendorong untuk mencapai tujuan organisasi. Pengaruh motivasi terhadap kinerja karyawan berdasarkan perhitungan regresi linear sederhana yang telah dilakukan bahwa koefisien korelasi antara motivasi terhadap kinerja karyawan sebesar 0,605 dan koefisien determinasi 36,60 \%. Hal ini berarti terdapat pengaruh yang kuat antara motivasi dan kinerja karyawan, dan berdasarkan pengujian hipotesis yang telah dilakukan dengan "Uji $\mathrm{t}$ " diperoleh bahwa $\mathrm{t}$ hitung $=4,691$ dan setelah dibandingkan dengan $\mathrm{t}$ tabel pada taraf signifikan $5 \%$ dan $\mathrm{n}=40$ menunjukkan $\mathrm{t}$ tabel $=2,024$. Karena $\mathrm{t}$ hitung lebih besar dari $\mathrm{t}$ tabel $(4,691>2,024)$ dengan demikian terbukti bahwa "Terdapat pengaruh yang signifikan antara motivasi terhadap kinerja karyawan pada PT. Fast Food Indonesia (KFC) Cabang Pondok Indah Plaza". Jika dilaksanakan kegiatan motivasi yang rutin pada PT. Fast Food Indonesia (KFC) Cabang Pondok Indah Plaza akan menciptakan karyawan-karyawan yang handal dan memiliki kemampuan serta keahlian yang dapat meningkatkan kinerjanya, hal ini dapat terlihat dari jawaban responden dengan 10 soal pernyataan dari setiap variabel bebas yang diberikan.

\section{Daftar Pustaka}

Amirullah. (2015). Pengantar Manajemen. Jakarta: Mitra Wacana Media

Ansory dan Meithiana. (2018). Manajemen Sumber Daya Manusia. Sidoarjo: Indomedia Pustaka.

Akdon dan Ridwan. (2013). Rumus Dan Data Dalam Analisis Statiskika. Bandung: Alfabeta.

Creswell, John W. 2014. Research Design: Pendekatan Kualitatif, Kuantitatif dan Mixed. Yogyakarta:Pustaka Pelajar.

Ghozali, Imam. (2018). Aplikasi Analisis Multivariate dengan Program IBM SPSS 25(2018). Semarang: Badan Penerbit Universitas Diponegoro.

Hasibuan. (2013). Manajemen Sumber Daya Manusia. Jakarta: PT. Bumi Aksara. (2014). Manajemen Sumber Daya Manusia. Jakarta: PT. Bumi Aksara.

Heryanto dan Triwibowo. (2018),Path Analysis Menggunakan SPSS dan EXCEL (Two In One - All Version) Panduan Pengolahan Data Penelitian untuk Skripsi/Tesis.Bandung: Informatika Bandung. 
Kaswan. (2012). Manajemen Sumber Daya Manusia Untuk Keunggulan Bersaing Organisasi. Yogyakarta: Graha ilmu.

Mangkunegara. (2014). Manajemen Sumber Daya Manusia Perusahaan. Bandung: PT. Remaja Rosdakarya.

. (2013). Manajemen Sumber Daya Manusia Perusahaan. Bandung: PT. Remaja Rosdakarya

. (2011). Manajemen Sumber Daya Manusia Perusahaan. Bandung: PT. Remaja Rosdakarya.

Riduwan. 2012. Metode \& Teknik Menyusun Proposal Penelitian. Bandung: Alfabeta.

Safroni, Ladzi. 2012. Manajemen dan Reformasi Pelayanan Publik dalam Konteks Birokrasi Indonesia. Surabaya : Aditya Media Publishing.

Sarwono, Jonathan. (2012). Metode Riset Skripsi Pendekatan Kuantitatif Menggunakan Prosedur SPSS (Edisi Pertama). Jakarta: PT Elex Media Komputindo.

Sugeng D. Triswanto. (2010). Trik Menulis Skripsi Dan Menghadapi Presentasi Bebas Stress. Yogyakarta: Tugu Publisher.

Sugiyono. (2017). Metode Penelitian Kuantitatif, Kualitatif, Dan R\&D. Bandung: Alfabeta, CV.

. (2014). Metode Penelitian Pendidikan Pendekatan Kuantitatif, Kualitatif Dan R\&D. Bandung: Alfabeta.

. (2013). Metode Penelitian Pendidikan Pendekatan Kuantitatif, Kualitatif Dan R\&D. Bandung: Alfabeta.

. (2011). Metode Penelitian Pendidikan Pendekatan Kuantitatif, Kualitatif Dan R\&D. Bandung: Alfabeta.

Suwanto. 2012. Manajemen Sumber Daya Manusia dalam Organisasi Publik dan Bisnis. Alfabeta. Bandung.

Priehadi Dhasa eka n Suwanto 2020, Audit Sumber Daya Manusia, Desanta Muliavisistama Suwanto 2020, Manajemen Sumber Daya Manusia , Desanta Muliavisistama.

Suwanto 2020, Strategi Pemberdayaan potensi pemuda karang taruna, Desanta Muliavisistama

Triana, E. (2015). Pengantar Manajemen (3 In 1). Kebumen: Mediatera.

Wibowo. (2013). Perilaku Dalam Organisasi. Jakarta: PT. Raja Grafindo .Persada.

Ariska.Deni (2015). Pengaruh Motivasi, Disiplin Kerja, Dan Keselamatan Kerja Terhadap Kinerja Karyawan Pada PT. Arumbai Kesembadan Banyumas. Manajemen Industrial, 6-11. Diakses pada 19 September 2019, dari:

http://Repository.Ump.Ac.Id/7547/3/bab\%20ii_Deni\%20ariska_Manajemen\%2718.Pdf. Jurnal Motivasi. Diakses pada 19 agustus 2019 (13.46), dari:

https://scholar.google.co.id/scholar?hl=id\&as_sdt=0\%2C5\&q=jurnal+motivasi\&btnG=. Jurnal Kinerja Karyawan. Diakses pada 19 Agustus 2019, dari:

https://scholar.google.co.id/scholar?q=jurnal+kinerja+karyawan\&hl=id\&as_sdt=0\&as_vis $=1 \&$ oi $=$ scholart

Sejarah Berdirinya KFC. Diakses pada 1 Oktober 2019, dari:

https://id.wikipedia.org/wiki/KFC

Sejarah Berdirinya KFC Indonsia. Diakses pada 1 oktober 2019 , dari:.http://pandri16.blogspot.com/2018/09/sejarah-perusahaan-kfc-di-dunia.html

http://sosiologis.com/metode-penelitian-

kuantitatif\#: :text=Metode\%20penelitian\%20kuantitatif\%20menggunakan\%20dat a,khusus\%20yang\%20dialami\%20oleh\%20populasi. 20 Juli 2020

https://www.alihamdan.id/jenis-penelitian/ 21 juli 2020 
https://www.maxmanroe.com/vid/umum/pengertian-penelitian.html 21 Juli 2020

https://www.google.com/search?q=kbbi+motivasi\&oq=kbbi+mot\&aqs=chrome.1.69i57j0

17.10503j0j7\&sourceid=chrome\&ie=UTF-8

https://scholar.google.co.id/scholar?hl=id\&as_sdt=0\%2C5\&q=regresi+excel+2007\&btnG=

Suwanto, S. (2019). Pengaruh Disiplin Kerja Dan Motivasi Kerja Terhadap Kinerja Karyawan Pada Rumah Sakit Umum Tangerang Selatan. JENIUS (Jurnal Ilmiah Manajemen Sumber Daya Manusia), 3(1), 16-23.

Suwanto, S. (2019). Pengaruh Disiplin Kerja Dan Motivasi Kerja Terhadap Kinerja Karyawan Pada Rumah Sakit Umum Tangerang Selatan. JENIUS (Jurnal Ilmiah Manajemen Sumber Daya Manusia), 3(1), 16-23.

Gandung, M., \& Suwanto, S. (2020). Analisis Pengaruh Kompensasi Dan Gaya Kepemimpinan Terhadap Kinerja Karyawan Pada PT. Surya Rasa Loka Jaya Di Jakarta Barat. JENIUS (Jurnal Ilmiah Manajemen Sumber Daya Manusia), 3(3), 236245.

Suwanto, S., Eka, P. D., Agusentoso, R., Juanda, A., \& Kurniawan, P. (2020). MENGGALI POTENSI, MEMOTIVASI DAN MENGARAHKAN GENERASI MUDA MENYONGSONG DUNIA KERJA PADA PKBM CIPTA TUNAS KARYA CIPONDOH KOTA TANGERANG. Jurnal Pengabdian Dharma Laksana, 2(2), 132-136.

Suwanto, S., \& Eka, P. D. (2020). Analysis Of Leadership Style Influence, Job Motivation, And Compensation Towards Teacher Satisfaction On The Foundation Of Al-Hasra Bojongsari. Depok City. International Journal of Advances in Social and Economics, 2(3).

SUWANTO, S. (2019). Pengaruh Gaya Kepemimpinan Dan Lingkungan Kerja Terhadap Kinerja Karyawan Unit Telesales Pada PT BFI Finance Indonesia TBK. Jurnal Ekonomi Efektif, 1(2). 